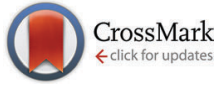

Cite this: Phys. Chem. Chem. Phys., 2015, 17, 27094

Received 5th August 2015, Accepted 15th September 2015

DOI: $10.1039 / c 5 c p 04636 j$

www.rsc.org/pccp

\title{
How to make a porphyrin flip: dynamics of asymmetric porphyrin oligomers $\dagger$
}

\author{
Cheng Shang, ${ }^{*} \ddagger$ Julian M. Philpott, $\ddagger$ Nick Bampos, Paul D. Barker and \\ David J. Wales*
}

\begin{abstract}
We present the first predictions of meso-aryl flipping pathways in porphyrin oligomers. In the context of cyclic oligoporphyrins this flipping results in a paddle rotation of each porphyrin monomer in the oligomeric ring. If the monomer porphyrin units are asymmetric, this flipping will have consequences for their supramolecular behaviour. Desymmetrisation of synthetic porphyrins leads to synthetic challenges, and hence these species are not as well studied as the more accessible, symmetric counterparts. We have both simulated and synthesized novel, desymmetrised monomeric and cyclic trimeric porphyrins and we predict that the flipping barrier for a porphyrin monomer within the trimer is $36.7 \mathrm{~kJ} \mathrm{~mol}^{-1}$ higher than that for meso-aryl flipping in the monomer. The flipping rates estimated from Variable temperature NMR data are consistent with these results. We have also carried out a systematic investigation of how porphyrinic substituents will affect the dynamics, revealing that adding steric bulk in the right place can facilitate meso-aryl flipping. While supramolecular chemistry often focuses on highly symmetric assemblies, evolution can break molecular symmetry in subtle ways, leading to many pseudosymmetric assemblies in biology, especially protein-porphyrinic complexes that are important for energy harvesting and electron transport systems. The dynamic behaviour we have characterized can be critical for the design and function of these molecules, and hence our results will help inform future efforts in the synthesis of asymmetric porphyrinic assemblies that interact with biomolecules.
\end{abstract}

\section{Introduction}

Consideration of dynamic behaviour is critical in the design and function of supramolecular assemblies, allowing complex architectures to form, ${ }^{1-3}$ which may then mediate selective binding and catalysis. ${ }^{4-7}$ Organised arrays of porphyrins play important roles in nature, especially in photosystems I and II, and light harvesting systems 1 and $2 .^{8-10}$ Circular porphyrin arrays also play important roles in recognition, light harvesting, and catalysis for supramolecular chemistry. ${ }^{5,11,12}$ In natural systems porphyrinic cofactors are organised by the protein structure through metal ligation and hydrophobic interactions, with no direct covalent linkage between porphyrins, in contrast to many artificial porphyrinic arrays. ${ }^{13-18}$ Does nature avoid linkage between these abundant prosthetic groups, or has it not discovered such structures yet? If naturally evolved porphyrins are yet to sample covalently linked structures, then it will be

University Chemical Laboratories, Lensfield Road, Cambridge CB2 1EW, UK.

E-mail: cs778@cam.ac.uk,dw34@cam.ac.uk

$\dagger$ Electronic supplementary information (ESI) available: Details of synthesis, COSY and TOCSY analysis of P1, the VT-NMR spectrum of P2, the NMR spectrum of $\mathbf{P 1}$ at $298 \mathrm{~K}$ in $\mathrm{d}_{8}$-toluene, Homo orbitals of P2 in SM, IM1, IM2 and IM3 and videos for the P2 flipping path. See DOI: 10.1039/c5cp04636j

‡ These authors contributed equally to this work. interesting to ask how we might integrate and exploit such nonnatural prosthetic groups within natural systems and what structural and dynamic factors are important. In this work we present a desymmetrised analogue of a well-studied cyclic porphyrin oligomer, which was designed to aid our understanding of porphyrin dynamics. Computational analysis is employed to provide insights that have been proven challenging to obtain from experimental measurements alone.

Many studies of porphyrin dynamics have focused on distortions of the core conformation, e.g. the characterization, the origin and their impact on the ligand binding to the central metal. ${ }^{19-22}$ Some other work has addressed synthesis of a series of oligomers with various cavity sizes and flexibilities by varying the linker between porphyrins. $^{23,24}$ The rotation of meso-aryl in the porphyrin monomer has been probed using both experiments and simulations for different substituents at the axial-, meso- and $\beta$-pyrrolic positions. ${ }^{25-30}$ Substituent effects at these sites are likely to be significant because of their impact on the geometric and electronic structures for putative supramolecular devices. In particular, the meso-aryl rotation is very important in the synthesis of unsymmetrical porphyrins and the corresponding oligomers. In 1975, Eaton et al. synthesized a series of tetraphenylporphyrins with different central metals and alternative substituents at the para-position of meso-aryl. ${ }^{25}$ The rotational barrier of the 

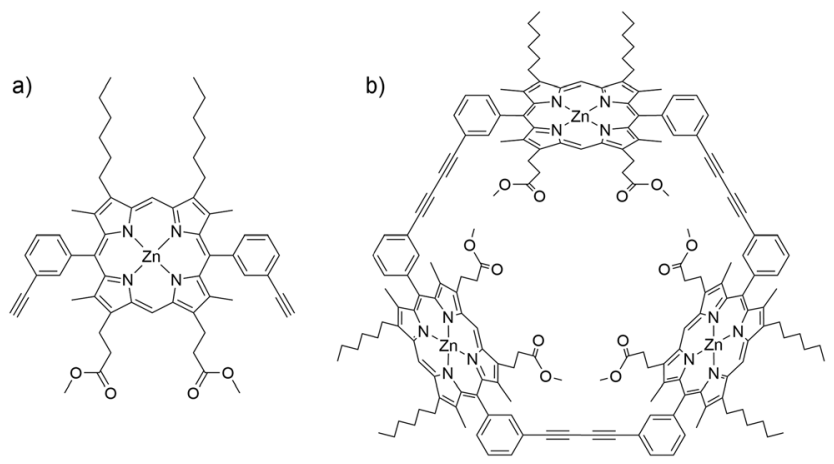

Fig. 1 Structures of (a) $\mathrm{ZnBAP}_{m}$ (P1) and (b) $\mathrm{Zn}_{3} \mathrm{TRI}_{m}$ (P2).

meso-phenyl group that was reported from variable temperature NMR was around 62 to $75 \mathrm{~kJ} \mathrm{~mol}^{-1}$. Similar results have also been obtained in the last decade using NMR, molecular mechanics, and higher level calculations. ${ }^{26-29}$ However, to the best of our knowledge, there have been no investigations into the flipping of a single macrocycle in a porphyrin oligomer.

In the present contribution, we combine experiment with analysis of pathways and rates, including explicit treatment of electronic structures, exploring the flipping of a porphyrin monomer, dimethyl 3,3'-(5,15-bis-(3-ethylphenyl)-8,12-dihexyl3,7,13,17-tetramethyl zinc porphyrin-2,18-diyl) dipropionate $\left(\mathrm{ZnBAP}_{m}, \mathbf{P 1}\right)$ in its cyclic trimer, $\mathrm{Zn}_{3} \mathrm{TRI}_{m}$ (P2, Fig. 1). We find that the flipping barrier of the monomer macrocycle in $\mathbf{P 2}$ is $36.7 \mathrm{~kJ} \mathrm{~mol}^{-1}$ larger than that associated with meso-aryl rotation in P1. A systematic investigation of the steric effect at the mesoand $\beta$-pyrrolic positions on the meso-aryl rotation in the monomer was also performed. A large substituent at the $\beta$-pyrrolic position is shown to decrease the flipping barrier, with important implications for the design and synthesis of porphyrin oligomers.

\section{Computational details}

The basin-hopping global optimisation algorithm ${ }^{31-33}$ implemented in our GMIN program ${ }^{34}$ was used to predict the initial structures of $\mathbf{P 1}$ and $\mathbf{P 2}$. The doubly ${ }^{35,36}$ nudged elastic band (DNEB) method, ${ }^{37}$ as implemented in the OPTIM program, ${ }^{38}$ was used to generate likely candidate structures for transition states (TSs) along pathways of interest. These candidate structures were then refined accurately using hybrid eigenvector-following. ${ }^{39,40}$ The two minima that each TS connects were identified by calculating approximate steepest-descent paths.

Both the AMBER ff99SB ${ }^{41-43}$ molecular mechanics force field and quantum mechanical (QM) calculations with explicit treatment of electronic structures were used to analyse the potential energy surface. The partial charges used to generate the AMBER force field were calculated using GAMESS ${ }^{44}$ at the B3LYP/6-31G* level $^{45-48}$ by the restricted electrostatic potential method. ${ }^{49}$ The force field parameters are a combination from the general AMBER force field (gaff) parameter set, ${ }^{50}$ parameters for heme from the AMBER parameter database, ${ }^{51}$ and parameters generated by Lin and Wang for zinc-containing compounds. ${ }^{52}$ Initially, potential energy surface exploration was performed for the
AMBER potential. The resulting minima and transition states were refined using the Gaussian 03 software package ${ }^{53}$ interfaced to OPTIM. The $\mathbf{P 1}$ and $\mathbf{P 2}$ optimization used the B3LYP functional and $6-31 \mathrm{G}(\mathrm{d}, \mathrm{p})$ basis sets first, followed by single point energy calculations using $6-31++\mathrm{G}(\mathrm{d}, \mathrm{p})$ to improve the possible nonbonded interactions. The $6-31 \mathrm{G}(\mathrm{d}, \mathrm{p})$ basis set has been used to investigate meso-aryl rotation in small porphyrin monomers. ${ }^{26}$ Then, another single point energy calculation with chloroform was represented by the polarizable continuum solvent model $(\mathrm{PCM})^{54,55}$ in Gaussian 03. In the subsequent analysis, optimization of all the monomers was performed at the B3LYP/ $6-31++\mathrm{G}(\mathrm{d}, \mathrm{p})$ level of theory in vacuum. The zero point energy was calculated using the AMBER force field for both P1 and P2.

\section{Results and discussion}

We present a detailed analysis of the predicted pathways between conformational isomers for a number of porphyrin systems. Our investigation begins with the novel porphyrin P1 and is extended to the cyclic trimer, $\mathbf{P 2}$, whose synthesis and NMR characterisation have allowed us to experimentally corroborate the computational results. In addition, we present a systematic study of $\beta$-pyrrolic and ortho-aryl substitution on the energy barriers for conformational exchange to inform future synthetic efforts.

\section{1 meso-Aryl flipping mechanism in P1}

3.1.1 Predicted characteristics of the flipping pathway. The global minimum of $\mathbf{P 1}$ employed as the starting minimum (SM) is the syn-conformer with respect to the two 3-ethynyl meso-aryl groups. Starting from this conformation the rotational pathway about the meso-aryl bond was calculated. The structures of key stationary points were identified (Fig. 2) and the corresponding energies are tabulated (Table 1). We note that in the initial structure the porphyrin macrocycle is slightly buckled, corresponding to a ruffle distortion. ${ }^{56}$ The $\beta$-hexyl groups are almost parallel to each other, with the $\beta$-ester groups antiparallel. The aryl substituents align perpendicular to the plane of the mesoand $\alpha$-pyrrolic carbons.

At the first transition state (TS1), significant distortion of the porphyrin ring is observed, which lifts the aryl group to a dihedral angle of $41.5^{\circ}$, with respect to the plane of the macrocycle. This distortion coincides with a small offset in the $\beta$-methyl substituents in the opposite direction. Thus, the steric clash between the ortho-protons and the $\beta$-methyl moieties is relieved in this transition state. The intermediate minimum (IM) exhibits a similar configuration and only a slight energy reduction relative to TS1 (Table 1). In the intermediate minimum the aryl group becomes coplanar with the porphyrin ring, producing a striking difference in the electronic character: conjugation extends over the aryl ring, inverting the energies of the HOMO and HOMO-1, as well as breaking the degeneracy of the LUMO and LUMO+1 (Fig. 3).

The second half of the pathway is similar to the first half in both energy and structure, resulting in a final minimum (FM) where the two aryl groups are now anti to each other. 

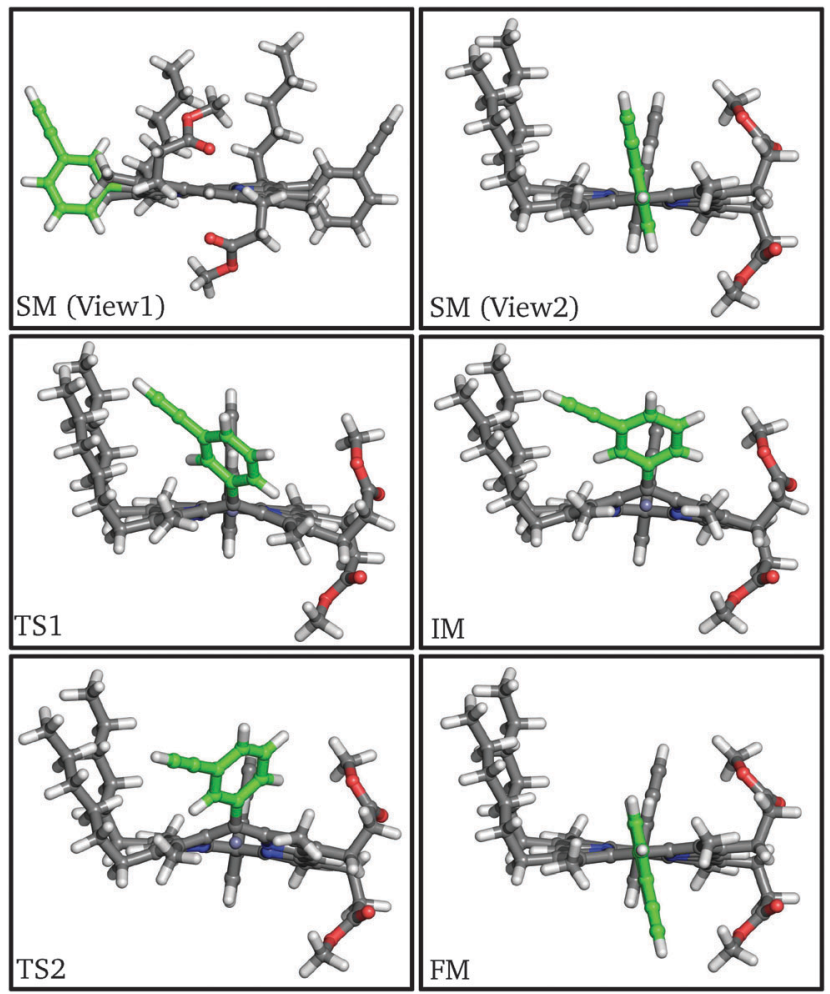

Fig. 2 Structures of stationary points along the meso-aryl rotational pathway for $\mathbf{P} \mathbf{1}$, highlighting the rotating aryl ring (green).

Table 1 Potential energy of each stationary point along the path corresponding to the starting minimum $\left(\mathrm{KJ} \mathrm{mol}^{-1}\right)$

\begin{tabular}{lrrrrr}
\hline & $\Delta E^{a}$ & $\Delta$ diff $^{b}$ & $\Delta$ solv $^{c}$ & $\Delta$ ZPE $^{d}$ & Final $^{e}$ \\
\hline SM & 0.0 & 0.0 & 0.0 & 0.0 & 0.0 \\
TS1 & 64.4 & +1.9 & -1.3 & -1.9 & 63.1 \\
IM & 59.0 & +3.3 & -1.1 & -3.0 & 58.2 \\
TS2 & 62.0 & +1.7 & -0.7 & -2.3 & 60.7 \\
FM & 0.4 & +0.5 & -0.6 & 0.0 & 0.3
\end{tabular}

${ }^{a}$ Potential energies evaluated using a $6-31 \mathrm{G}(\mathrm{d}, \mathrm{p})$ basis set. ${ }^{b}$ Energy differences contributed by the diffuse basis set. ${ }^{c}$ Energy differences contributed by the solvent effect. ${ }^{d}$ Energy differences contributed by the zero point energy. ${ }^{e}$ The sum of all the terms.

Other than this anti configuration, the final minimum is almost identical to the initial minimum, and the energy profile of the whole process is roughly symmetrical and thermoneutral, with a barrier of $63.1 \mathrm{~kJ} \mathrm{~mol}^{-1}$, which corresponds to a rate constant of $63.8 \mathrm{~s}^{-1}$ at $300 \mathrm{~K}$ according to transition state theory for harmonic normal mode frequencies. The energy barrier and the conformational changes presented here are consistent with our experimental results from variable-temperature NMR (VT-NMR) spectroscopy (see below), as well as previous experiments and simulations. ${ }^{25-29}$

3.1.2 VT-NMR spectroscopy of P1 and P3. Proton NMR of P1 (298 $\mathrm{K}$ in $\mathrm{d}_{8}$-toluene) produces a well-defined and predictable spectrum, with one subtle discrepancy: the resonance at $7.35 \mathrm{ppm}$ appears as a doublet of triplets where a triplet would be expected for this proton environment (peak 4 in Fig. 4). Upon increasing
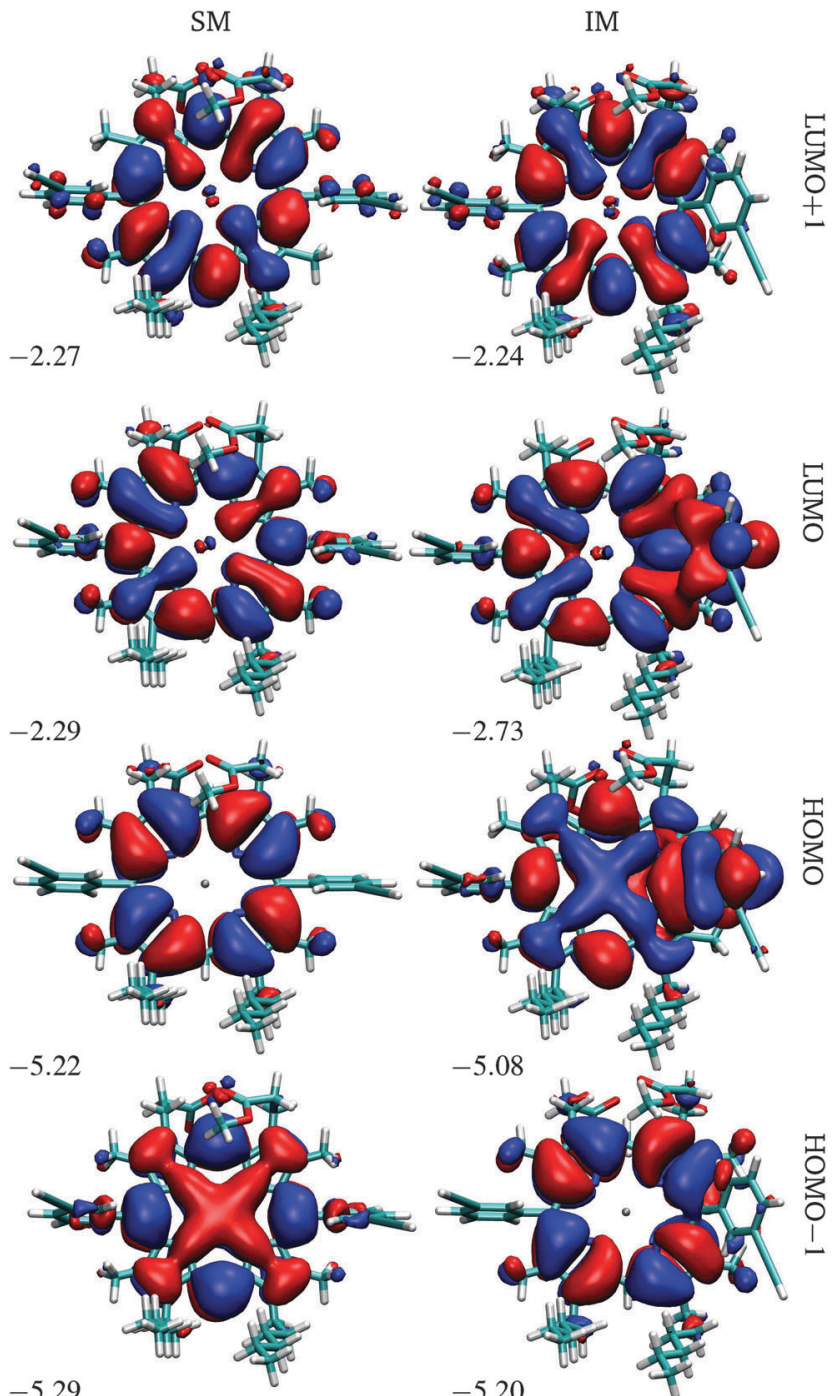

$-5.29$

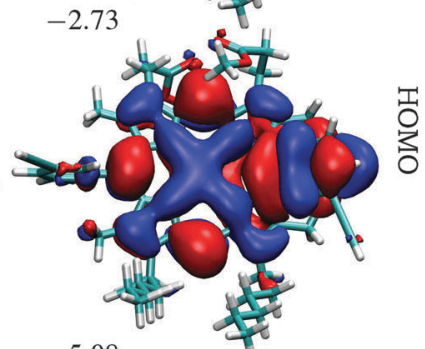

Fig. 3 Frontier orbitals of $\mathbf{P} \mathbf{1}$ in the starting and intermediate minima, $\mathrm{SM}$ and IM. The energies are in $\mathrm{eV}$.

the temperature the expected triplet is observed. However, when the temperature is lowered a significant change occurred, as the triplet deconvolves into two signals. At $223 \mathrm{~K}$ seven aryl resonances are observed, in place of the expected four, using COSY and TOCSY analysis (ESI $\dagger$ ) suggesting the presence of two different spin systems. Only the resonance associated with proton 5 , which is coaxial with the meso-aryl bond, does not deconvolve into two signals and remains common to both spin systems.

We interpret this behaviour in terms of interconversion between the syn and anti atropisomers that arise due to hindered rotation around the meso-aryl bond. Typical first order coalescence behaviour is not seen in this system, which may be due to a dependence of the rate of meso-aryl rotation on the rate of porphyrin ring buckling, giving rise to the observed changes in shift rather than classical coalescence, similar to the work published by Deeming et al. ${ }^{57}$

To confirm that this observation is not a result of the asymmetrical nature of P1 these experiments were also conducted on 
(a)

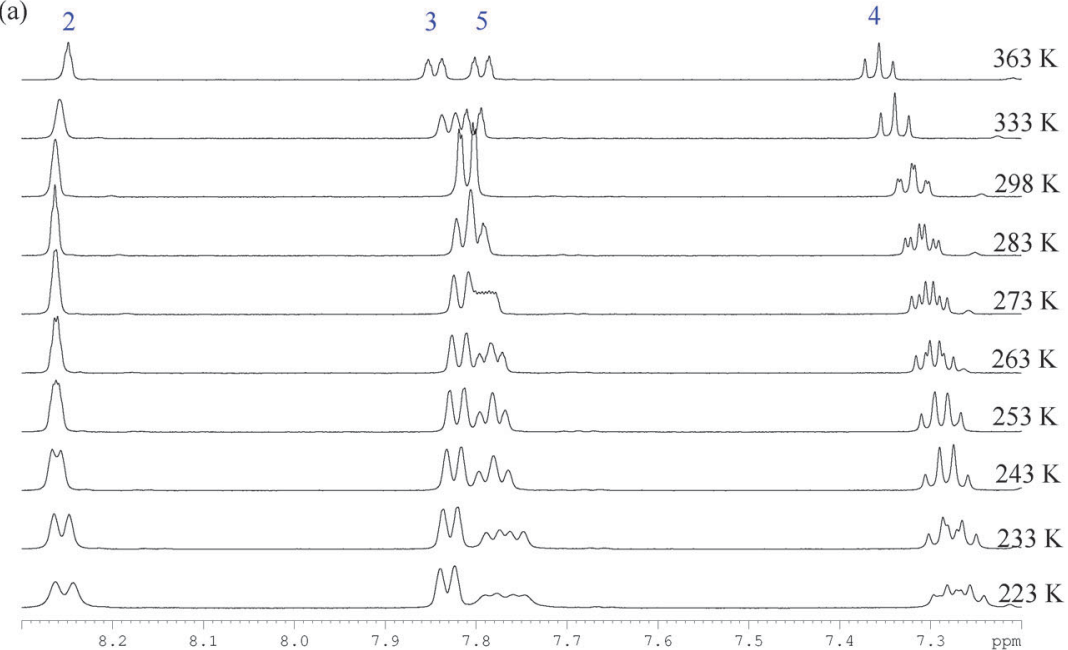

(b)

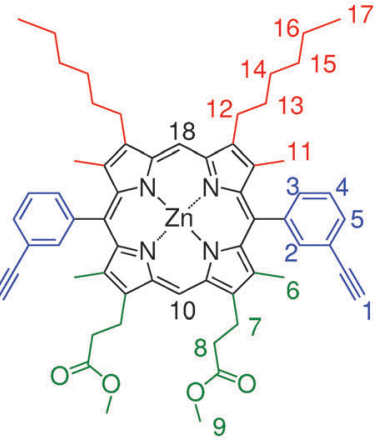

Fig. 4 (a) ${ }^{1} \mathrm{H}$ VT-NMR spectra collected in the aromatic region of $\mathbf{P} 1$ ( $\mathrm{d}_{8}$-toluene, temperatures ranging from $223-363 \mathrm{~K}$ ). (b) The structure and assignment of $\mathbf{P} \mathbf{1}$.

$\mathrm{ZnBAP}_{b}(\mathbf{P} 3)$, the symmetrical tetra-hexyl analogue of $\mathbf{P 1}$, which was prepared according to the literature method. ${ }^{58}$ Very similar temperature dependent behaviour was observed, demonstrating that the $\beta_{2}$ substitution has little effect. Spectra collected for P1 in $d_{5}$-pyridine also produce the same results, ruling out facial stacking and porphyrin aggregation phenomena as the origin of the deconvolution of aryl signals. We have considered whether these observations might be a result of thermal averaging that prevents the resolution of the locked atropisomers at increased temperatures, as opposed to our hypothesis that the NMR timescale is around that of the rotation rate. However, reported yields ( 50 to $55 \%)^{59}$ for the synthesis of a cyclic trimer are inconsistent with a system containing conformationally locked atropisomers, where only the syn form is disposed to form the cyclic trimer.

$\Delta G^{\ddagger}$ for rotation was estimated as $\Delta G^{\ddagger}=a T\left[9.972+\ln \left(T_{\mathrm{C}} / \Delta u\right)\right]$, where $\Delta G^{*}$ is the Gibbs free energy required for rotation at temperature $T, a$ is a constant equal to $1.914 \times 10^{-2} \mathrm{~kJ} \mathrm{~mol}^{-1}$, $T_{\mathrm{C}}$ is the temperature of coalescence, and $\Delta u$ is the frequency difference of the chemically equivalent resonances in the slow exchange limit. ${ }^{60} T_{\mathrm{C}}$ was obtained by plotting $\Delta u$ versus $T$ for the dynamic range in the VT-NMR and the results for $\Delta G^{\ddagger}$ are presented in Table 2. From these data we estimate $\Delta G^{\ddagger}$ for rotation about the meso-aryl bond to be $65.4 \mathrm{~kJ} \mathrm{~mol}^{-1}$. This value is in reasonable agreement with the calculated energy barrier of $63.1 \mathrm{~kJ} \mathrm{~mol}^{-1}$.

Table 2 Experimentally derived Gibbs free energy of meso-aryl rotation for P1

\begin{tabular}{llr}
\hline Proton assignment & $\Delta G^{\ddagger}(298 \mathrm{~K}) /\left(\mathrm{kJ} \mathrm{mol}^{-1}\right)$ & Error \\
\hline 1 & 66.8 & 0.65 \\
2 & 65.1 & 1.81 \\
3 & 64.9 & 19.07 \\
4 & 64.8 & 1.20 \\
Average & 65.4 &
\end{tabular}

\subsection{Rotational pathway in the cyclic porphyrin trimer, $\mathbf{P 2}$}

3.2.1 Predicted flipping pathway. An initial structural model for $\mathbf{P 2}$ was obtained by the removal of alkynyl protons and the combination of three P1 monomers (Fig. 5 and videos, see ESI $\dagger$ ). The relaxed structure closely resembles the crystal structure of a previously reported related cyclic trimer. ${ }^{61}$ In this $C_{3}$ symmetric oligomer the three units are identical and preserve the monomeric structure closely. Subsequent global optimization using GMIN and the AMBER force field identified several new local minima, which were proved to be less stable than the initial structure when relaxed using explicit treatment of the electronic structure. Hence the original structure was used as the starting minimum (SM) for the pathway analysis. For convenience the rotating monomer is labelled M1 and the other monomers, M2 and M3, passively adjust their configurations to make room for the M1 flipping (Fig. 5). For the initial minimum the individual porphyrin macrocycles are perpendicular to the trimer equator, so M1 could follow two inversion paths. Here we focus on the rotation that makes the $\beta$-pyrrolic hexyl chains remain on the exterior, whilst the $\beta$-pyrrolic ester groups traverse the trimer interior. The other path is very similar to this one but with a slightly higher energy barrier, probably due to the differences in steric interactions.

In order for the rotation of M1 to occur both aryl rings must rotate about the meso-aryl bond, changing from the synconformation via the anti-conformation (IM2) back to the synconformation. The local configuration of M1 at TS1, IM1 and TS2 closely matches the corresponding stationary points in P1: $\mathrm{C}_{\beta}-\mathrm{C}_{m}-\mathrm{C}_{\beta}$ distorts out of the porphyrin plane and the $\beta$-methyl groups bend in the opposing direction to allow aryl ring rotation. No significant orientational or conformational changes in M2 and M3 are observed until IM1, at which point the aryl rings of M1 are perpendicular, causing M2 and M3 to adjust their positioning, while the butadiene linkers bend to accommodate the strained configuration. This bending manifests itself as a tilt 


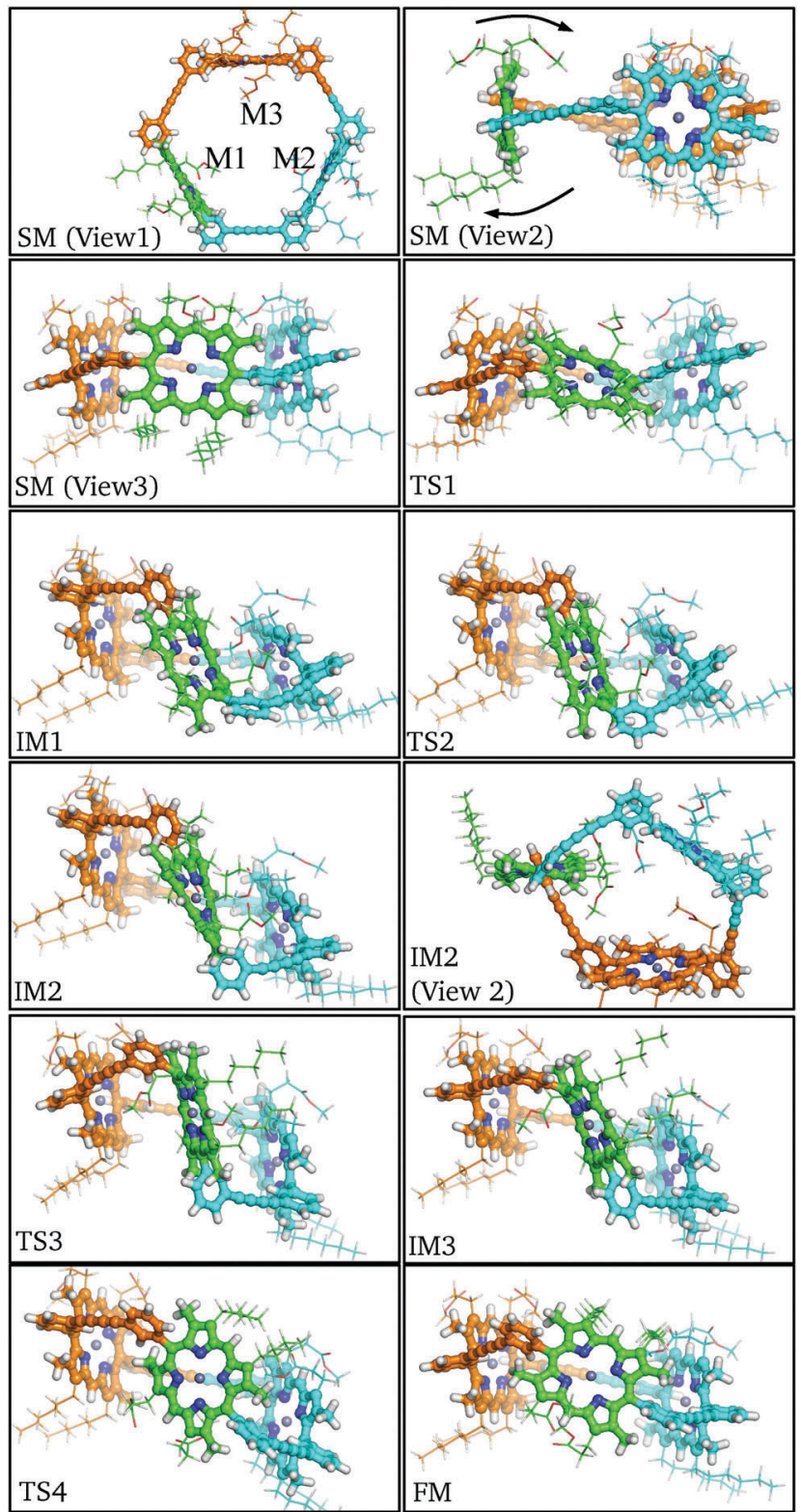

Fig. 5 Key structures along the rotational pathway for P2. The monomeric units are identified as the rotating M1 (green), static M2 (cyan), and static M3 (orange). For clarity, the aryl substituents of M1 are coloured as for the adjacent M2 and M3. The flipping direction is labelled in the starting minimum (view2).

in the rotational axis of $\mathrm{M} 1$ by around $45^{\circ}$ from the starting minimum to intermediate minimum IM1.

Following the pathway from IM1 to IM3 reveals little change in the tilt of the M1 rotational axis, and the M2 and M3 conformations remain relatively constant. This section of the pathway makes the flip and inversion of M1 via IM2, which is analogous to the final minimum for the $\mathbf{P 1}$ pathway. Two notable differences are observed: (i) the anti-aryl groups are now closer to perpendicular, creating a torsional angle of about $45^{\circ}$ along the meso-aryl bond, which serves to accommodate the conformation restraints imposed by M2 and M3. (ii) M1 is more buckled than the monomer in the anti-conformer, in contrast to the closer planarity of both M2 and M3. The greater strain at intermediate minimum IM2 results in destabilization relative to the starting minimum by $37.8 \mathrm{~kJ} \mathrm{~mol}^{-1}$.

Beyond intermediate minimum IM2 a nearly identical reverse pathway is observed, but with rotation about the second aryl ring. In the final minimum the $C_{3}$ symmetry is broken relative to the starting minimum, due to the exchange of the $\beta$-pyrrolic hexyl and methyl-propionate side chains, resulting in $C_{\mathrm{s}}$ symmetry. There are other subtle configurational differences, especially the increased buckling of M1 and decreased buckling of M2. The result of these changes is that the final minimum is $6.8 \mathrm{~kJ} \mathrm{~mol}^{-1}$ higher in energy than the initial minimum. The highest energy barrier found corresponds to TS2 at $101.5 \mathrm{~kJ} \mathrm{~mol}^{-1}$, with an increase of $37.6 \mathrm{~kJ} \mathrm{~mol}^{-1}$ relative to the monomeric case. This significant energy barrier increase is predicted to reduce the rate constant for rotation in the trimer to around $10^{-5} \mathrm{~s}^{-1}$ at $300 \mathrm{~K}$.

The intrinsic barrier difference between $\mathbf{P 1}$ and $\mathbf{P 2}$, i.e. $\Delta E$ for TS1 in Tables 1 and 3, which is caused by the conformational constraint between monomers in $\mathbf{P 2}$, is only $16.2 \mathrm{~kJ} \mathrm{~mol}^{-1}$. The diffuse basis set and the solvent effect contribute little to the flipping barrier in P1, but change the energy of IM1 and TS2 significantly. The energy increase caused by the diffuse basis set ( $\Delta$ diff) is due to the repulsion between two $\beta$-pyrrolic ester groups of M1 and M2 during M1 flipping. The largest $\Delta$ diff corresponds to IM1 and TS2 in $\mathbf{P 2}\left(+13.3 \mathrm{~kJ} \mathrm{~mol}^{-1}\right)$ and decreases with the repulsion between ester groups. The energy increase caused by the solvent effect ( $\Delta$ solv) is a result of the burial of the $\beta$-pyrrolic ester groups within the macrocycle, thus reducing the surface area and the polarity of the molecule compared to the initial minimum. Notably, the same striking conjugation of the meso-aryl orbitals with the porphyrin core seen in IM of P1 (Fig. 3) is observed in the HOMO of IM1 and IM3 in similar calculations of $\mathbf{P} 2$ (see ESI $\dagger$ ).

3.2.2 VT-NMR spectrum of $\mathbf{P 2}$. The design of $\mathbf{P 2}$ was intended to provide insight into the rotational behaviour of monomeric units within oligomeric macrocycles. The peripheral protons in the system were expected to act as markers to report on the conformational state of the oligomer, which has two distinct orientations in the low energy state, P2-SM, where porphyrin units present their $\beta$-pyrrolic side chains unidirectionally, or P2-FM, where one unit directs its $\beta$-pyrrolic side chains antiparallel to the other two units. For example, in the initial minimum we expected two meso proton signals, and in the final

Table 3 Potential energy of each stationary point along the predicted pathway for rotation in $\mathbf{P} 2\left(\mathrm{~kJ} \mathrm{~mol}^{-1}\right)$

\begin{tabular}{lrrrrr}
\hline & \multicolumn{1}{c}{$\Delta E$} & $\Delta$ diff & $\Delta$ solv & $\Delta$ ZPE & Final \\
\hline SM & 0.0 & 0.0 & 0.0 & 0.0 & 0.0 \\
TS1 & 80.6 & +4.7 & +6.0 & -3.1 & 88.2 \\
IM1 & 64.2 & +13.3 & +9.9 & -1.3 & 86.1 \\
TS2 & 76.3 & +13.3 & +10.5 & +1.2 & 101.5 \\
IM2 & 18.3 & +10.9 & +6.8 & +1.7 & 37.8 \\
TS3 & 81.3 & +7.5 & +5.2 & +0.4 & 94.4 \\
IM3 & 67.0 & +7.2 & +4.3 & -1.2 & 77.2 \\
TS4 & 82.5 & +4.0 & +2.9 & -0.9 & 88.5 \\
FM & 2.6 & +3.0 & +1.2 & 0.0 & 6.8
\end{tabular}


minimum four, a total of six meso environments for a statistical mixture of the $\mathbf{P 2}$ local minima corresponding to slow exchange.

The ligand 2,4,6-tri(pyridine-4-yl)-1,3,5-triazine, TPyT, was added to obtain a spectrum of $\mathbf{P 2}$ in a rotationally locked state. TPyT is known to bind with chelate cooperatively into analogous cyclic zinc porphyrin trimers with association constants between $9 \times 10^{9}$ and $4 \times 10^{10} \mathrm{~mol}^{-1} \mathrm{dm}^{3}$ through nitrogen-zinc ligation. ${ }^{62}$ In this TPYT bound configuration, it is assumed that the porphyrin units are fixed and prevent monomer inversion.

${ }^{1} \mathrm{H}$ NMR spectra of $\mathbf{P} 2\left(\mathrm{~d}_{8}\right.$-toluene, $\left.298 \mathrm{~K}\right)$ with TPyT bound exhibit six meso proton environments in addition to a deconvolution of signals attributed to the alkyl and ester side chains (Fig. 6). Signals at 2.80 and $5.20 \mathrm{ppm}$ are characteristic of heavily shifted (lower ppm) TPyT signals caused by binding within the trimer; there is no observable unbound ТРУT in solution. Therefore it is clear that porphyrin unit flipping is not seen on this time scale and we observe a statistical mixture of P2-IM and P2-FM. If the temperature is increased, resolution of the six meso-environments becomes difficult, the TPyT signals broaden, and separate side chain signals are no longer distinguishable. However, there remains no evidence that ТРУТ becomes unbound from P2, suggesting that thermal averaging hampers the distinction between P2-IM and P2-FM, but does not facilitate interconversion $(\mathrm{ESI} \dagger)$. Cooling this sample (min. $223 \mathrm{~K}$ ) produces no significant differences in comparison to the measurement at $298 \mathrm{~K}$. At all temperatures not more than four aryl signals were characterised, suggesting that only the meso-aryl syn conformation is observable, in view of the other evidence presented above.
The same sample in $\mathrm{d}_{5}$-pyridine shows displacement of TPуT by the solvent, two apparent meso signals, no deconvolution of side chain resonances, and four aryl signals. Variable temperature NMR of this system shows no deconvolution or sharpening of proton resonances. We ascribe this behaviour to a system where P2-IM and P2-FM are both present in solution, but are not interconverting. However, they remain indistinguishable by NMR due to thermal averaging of the peripheral protons, which can sample many more environments without the locking influence of the ТРУT ligand. If this is the case, the energy barrier for flipping is significantly higher for P2 than the energy barrier of rotation is for $\mathbf{P 1}$.

\subsection{The effect of substituents on meso-aryl flipping}

For a more general, systematic study we have considered the effect of a range of $\beta$-pyrrolic substituents on aryl group rotational barriers. The aim here is to guide the modification of the porphyrin to facilitate or restrain aryl motion, which is important for synthesis, to prevent scrambling of moieties, and for twisting oligoporphyrin properties. The results are organised according to modification at the two $\beta$-pyrrolic positions and the orthoposition on meso-aryl (Table 4, Fig. 8).

Perhaps counterintuitively, increasing the steric bulk at $\beta_{1}$ (the closest pyrrolic group to the aryl, Fig. 7) results in a decrease in rotational barriers for the aryl substituents corresponding to P1. For $\beta_{1}=\mathrm{H}$ and $\mathrm{CH}_{3}$ the porphyrin remains planar, while bulkier groups induce a steric clash, causing buckling of the porphyrin ring, destabilizing the starting minimum.

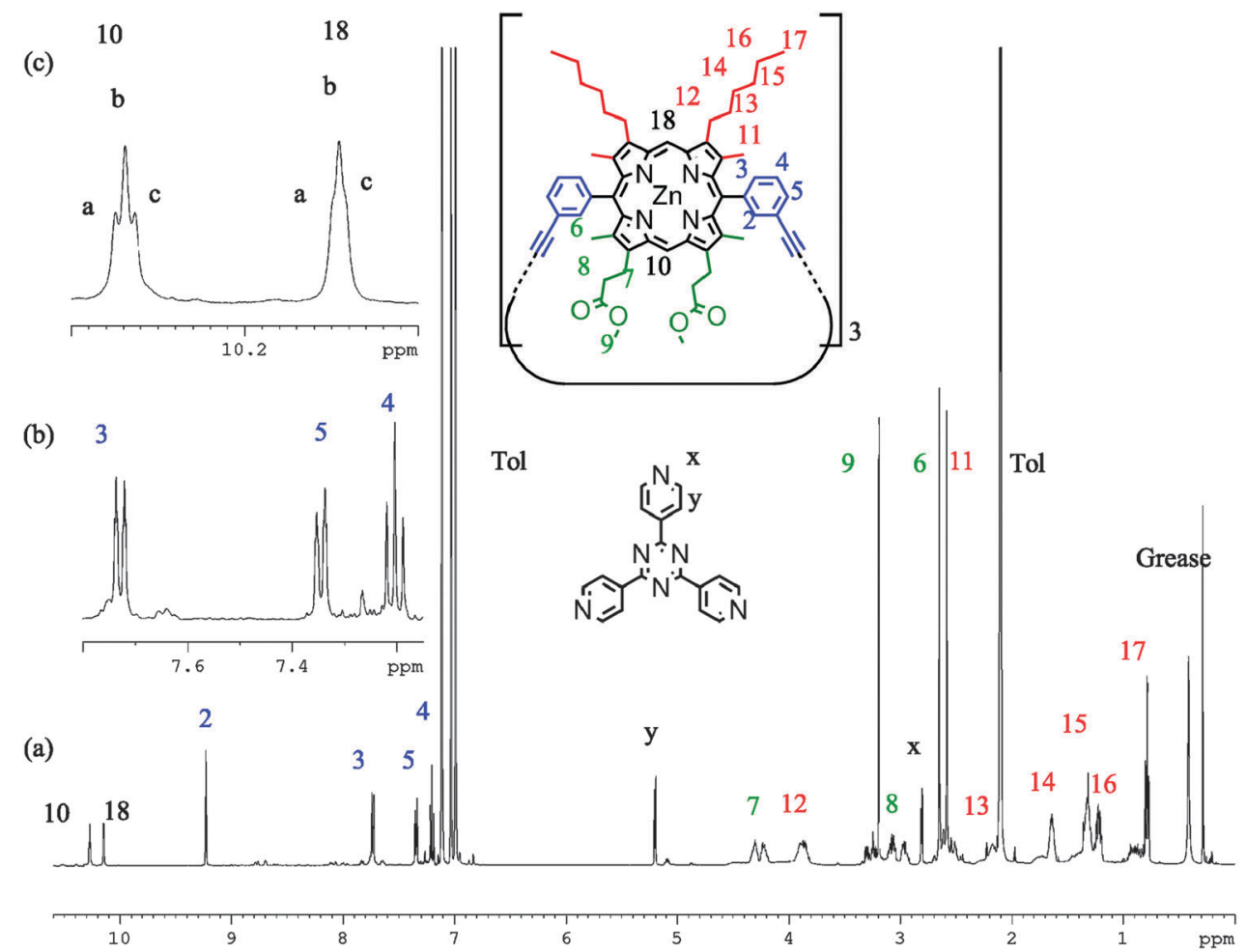

Fig. $6{ }^{1} \mathrm{H}$ NMR spectra of $\mathbf{P} 2$ with TPyT bound $\left(298 \mathrm{~K}, \mathrm{~d}_{8}\right.$-toluene, $700 \mathrm{MHz}$ ) showing (a) the proton assignment, (b) expanded regions of the aryl signals, and (c) the meso environments. 
Table 4 The energy barrier for meso-aryl flipping with different substituents at the $\beta_{1}, \beta_{2}$ and ortho positions corresponding to $\mathbf{P} \mathbf{1}\left(\mathrm{kJ} \mathrm{mol}{ }^{-1}\right.$ )

\begin{tabular}{llllr}
\hline & $\beta_{1}$ & $\beta_{2}$ & ortho & Barrier \\
\hline 1 & $\mathrm{H}$ & $\mathrm{H}$ & $\mathrm{H}$ & 77.1 \\
2 & $\mathrm{CH}_{3}$ & $\mathrm{H}$ & $\mathrm{H}$ & 75.6 \\
3 & $\mathrm{C}_{2} \mathrm{H}_{5}$ & $\mathrm{H}$ & $\mathrm{H}$ & 70.1 \\
4 & $\mathrm{NO}_{2}$ & $\mathrm{H}$ & $\mathrm{H}$ & 53.8 \\
5 & $\mathrm{CF}_{3}$ & $\mathrm{H}$ & $\mathrm{H}$ & 48.8 \\
6 & $\mathrm{CCl}_{3}$ & $\mathrm{H}$ & $\mathrm{H}$ & 27.8 \\
7 & $\mathrm{C}\left(\mathrm{CH}_{3}\right)_{3}$ & $\mathrm{H}$ & $\mathrm{H}$ & 30.4 \\
8 & $\mathrm{H}$ & $\mathrm{C}_{2} \mathrm{H}_{5}$ & $\mathrm{CH}_{3}$ & 182.7 \\
9 & $\mathrm{CH}_{3}$ & $\mathrm{C}_{2} \mathrm{H}_{5}$ & $\mathrm{CH}_{3}$ & 170.6 \\
10 & $\mathrm{CH}_{3}$ & $\mathrm{C}_{2} \mathrm{H}_{5}$ & $\mathrm{OCH}_{3}$ & 132.2 \\
11 & $\mathrm{H}$ & $\mathrm{C}_{2} \mathrm{H}_{5}$ & $\mathrm{H}$ & 76.9 \\
12 & $\mathrm{CH}_{3}$ & $\mathrm{C}_{2} \mathrm{H}_{5}$ & $\mathrm{H}$ & 66.1 \\
13 & $\mathrm{C}_{2} \mathrm{H}_{5}$ & $\mathrm{C}_{2} \mathrm{H}_{5}$ & $\mathrm{H}$ & 60.3 \\
14 & $\mathrm{NO}_{2}$ & $\mathrm{C}_{2} \mathrm{H}_{5}$ & $\mathrm{H}$ & 56.3 \\
15 & $\mathrm{C}\left(\mathrm{CH}_{3}\right)_{3}$ & $\mathrm{C}_{2} \mathrm{H}_{5}$ & $\mathrm{H}$ & 50.1 \\
& & & &
\end{tabular}

This prebuckling behaviour lifts the aryl ring out of plane in an opposing direction to that in which the $\beta$-substituents are forced, so rotation becomes easier, as all pathways require the same degree of buckling for rotation to occur. In summary, increased bulk at the $\beta_{1}$ positions destabilizes the starting minimum by forcing a buckled conformation, reducing the barrier for rotation by up to $46.7 \mathrm{~kJ} \mathrm{~mol}^{-1}$. It is worth noting that the idea of destabilizing the starting minimum to improve the activity shares similarity with the steric nature of the bite angle in catalysis. ${ }^{63,64}$

Now considering $\beta_{2}$ substitution, two different trends are observed in the $\beta_{2}-\mathrm{H}$ and $\beta_{2}-\mathrm{C}_{2} \mathrm{H}_{5}$ analogues. With low steric bulk in the $\beta_{1}$ position and increasing bulk at the $\beta_{2}$ position the same trend appears as above: pre-buckling in the starting minimum reduces the energy barrier for aryl rotation (Table 4: $1+11,2+12,2+14)$. With greater steric bulk at $\beta_{1}$ and increasing bulk at the $\beta_{2}$ position, the effect vanishes, and even reverses (Table 4: $4+14,7+15$ ), which might result from the repulsion between $\beta_{1}$ and $\beta_{2}$, inhibiting $\beta_{1}$ from moving into the optimal position at the TS. In addition to porphyrin monomer variations, the $\beta_{2}$-groups in $\mathbf{P 2}$ have all been substituted with $\beta_{2}-\mathrm{C}_{2} \mathrm{H}_{5}$ to correlate how substituents affect the flipping of a porphyrin unit in the trimer (Table 5). It is observed that upon reducing the size and the polarity of the $\beta_{2}$-group in $\mathbf{P 2}$, the intrinsic energy barrier remains almost unchanged. However,

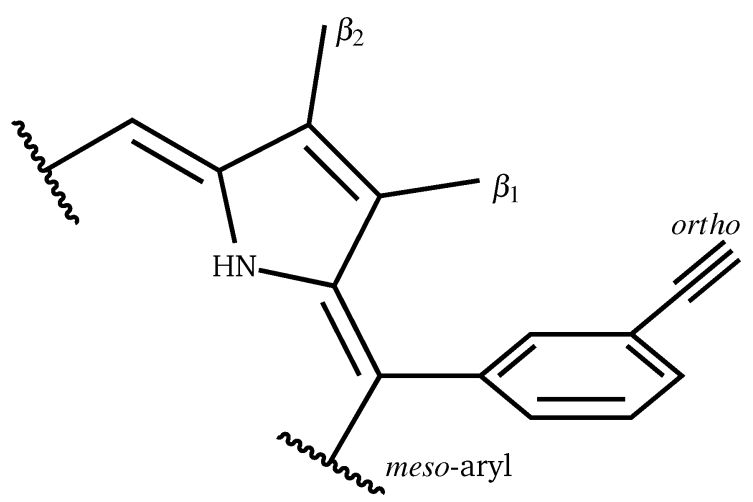

Fig. 7 Definition of the $\beta_{1}, \beta_{2}$ and meso positions.
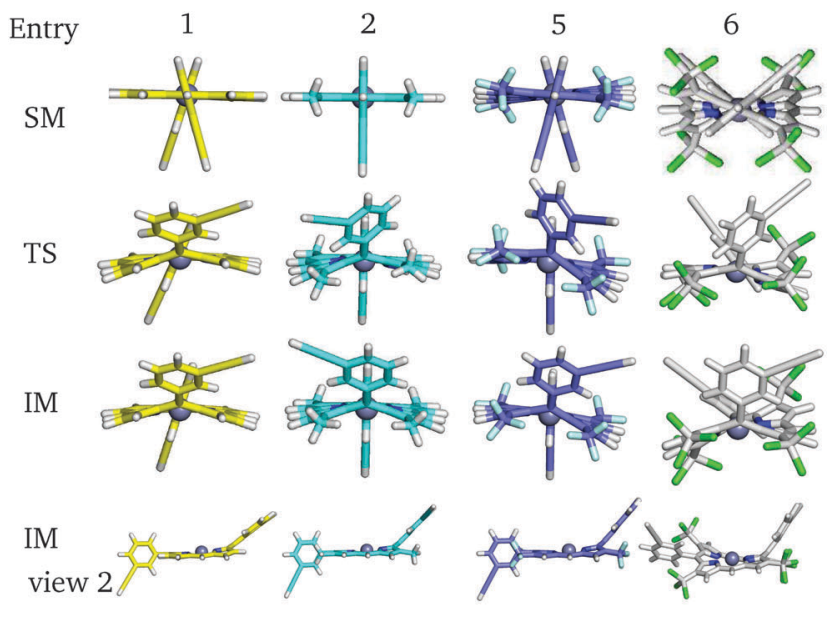

8

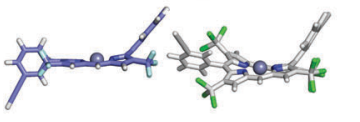

SM

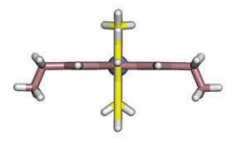

12

13

TS
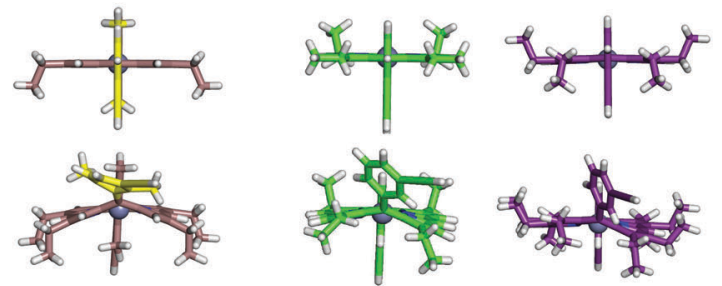

M
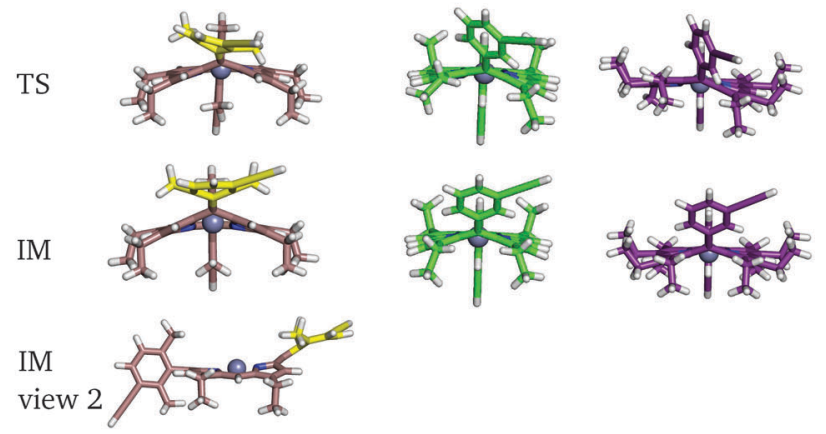

Fig. 8 Some key stationary points in the flipping paths with different substituents, corresponding to Table 4.

$\Delta$ diff and $\Delta$ solv are significantly reduced and the barrier comes down to $80.1 \mathrm{~kJ} \mathrm{~mol}^{-1}$, supporting the hypothesis we made in the last section. Hence, the $\beta_{2}$-ester and $\beta_{2}$-alkyl groups in P1 and $\mathbf{P 2}$ promote meso-aryl bond rotation in P1, but inhibit monomer flipping in $\mathbf{P 2}$.

Substitution at the 2,6-aryl positions is a common strategy for preventing meso-substituent scrambling in the rational synthesis of asymmetric porphyrins, which would otherwise lead to lower yields and difficulties in chromatographic separation. ${ }^{65-67}$

Table 5 Potential energy of each stationary point relative to the starting minimum (SM) along the rotational pathway of $\mathbf{P} \mathbf{2}$ with $\beta_{2}-\mathrm{C}_{2} \mathrm{H}_{5}$ as substituents $\left(\mathrm{kJ} \mathrm{mol}^{-1}\right)$

\begin{tabular}{lrrrrr}
\hline & $\Delta E$ & $\Delta$ diff & $\Delta$ solv & $\Delta$ ZPE & Final \\
\hline SM & 0.0 & 0.0 & 0.0 & 0.0 & 0.0 \\
TS1 $^{a}$ & 78.2 & +2.6 & +0.1 & -1.6 & 79.2 \\
IM1 & 62.7 & +2.9 & 0.0 & -3.5 & 62.1 \\
TS2 & 78.1 & +3.0 & +1.0 & -2.0 & 80.1
\end{tabular}

${ }^{a}$ By replacing all the $\beta_{2}$-substituents with $\beta_{2}-\mathrm{C}_{2} \mathrm{H}_{5}$, the porphyrin trimer becomes symmetric, and TS1 and TS4, IM1 and IM3, TS2 and TS3, and SM and FM become identical within the pairs. 
It is generally accepted that the ortho-substitution of the aryl ring prevents coplanarity of the aryl ring and the pyrrole, which would stabilize the cationic azafulvenium by aromatization. Hence we investigated the rotational energy barrier for the 2,6-dimethyl substituted aryl porphyrin analogues, which was found to be remarkably high, namely 182.7 and $170.6 \mathrm{~kJ} \mathrm{~mol}^{-1}$ (Table 4 entries $8+9$ ). These calculations agree with synthetic efforts, confirming that rotation at room temperature is extremely unlikely for the dimethyl analogue. For the $O$-methyl analogue (Table 4 entry 10) a lower barrier of $132.2 \mathrm{~kJ} \mathrm{~mol}^{-1}$ is predicted. This intermediate result fits with the observation that, in some cases, synthetic scrambling occurs despite the presence of 2,6-aryl substitution. In this case the electron donating nature of the $O$-methyl moieties may also play an important role in the stabilisation of the cationic azafulvenium, thereby facilitating scrambling.

\section{Conclusions}

We have synthesized a novel asymmetric porphyrin, $\mathrm{ZnBAP}_{m}$, and its cyclic trimer, $\mathrm{Zn}_{3} \mathrm{TRI}_{m}$. Calculations beginning with empirical force fields, and extending to explicit consideration of electronic structure, were used to predict the flipping pathway for the meso-aryl group in both the monomeric and trimeric species. The calculated energy barrier is $63.1 \mathrm{~kJ} \mathrm{~mol}^{-1}$, in good agreement with the results from variable temperature NMR spectroscopy, which yields a value of $65.4 \mathrm{~kJ} \mathrm{~mol}^{-1}$. The flipping pathway of a $\mathrm{ZnBAP}_{m}$ monomer in its trimer has also been predicted at the same levels of theory. The corresponding barrier is found to be much higher than for meso-aryl flipping in the monomer, in agreement with the NMR analysis. We carried out a set of calculations to systematically investigate how different substituents at the meso and $\beta$ positions affect the dynamic behaviour. The results show that steric effects in certain locations can effectively facilitate the flipping. A methyl group at the ortho-position of meso-aryl is predicted to increase the barrier by up to 170 to $180 \mathrm{~kJ} \mathrm{~mol}^{-1}$, while a methoxyl group increases the barrier to $132.2 \mathrm{~kJ} \mathrm{~mol}^{-1}$. These results will be used to guide the design and synthesis of porphyrin oligomers in future experiments.

\section{Acknowledgements}

This work was supported by the ERC, the EPSRC (EP/I001352/1) and the EPSRC via NanoDTC (EP/G0606491/1). Additional data related to this publication is available at the Cambridge Data Repository (https://www.repository.cam.ac.uk/handle/1810/251055).

\section{References}

1 N. Ponnuswamy, F. B. L. Cougnon, J. M. Clough, G. D. Pantos and J. K. M. Sanders, Science, 2012, 338, 783-785.

2 J.-F. Ayme, J. E. Beves, D. A. Leigh, R. T. McBurney, K. Rissanen and D. Schultz, J. Am. Chem. Soc., 2012, 134, 9488-9497.

3 C. J. Bruns, D. Fujita, M. Hoshino, S. Sato, J. F. Stoddart and M. Fujita, J. Am. Chem. Soc., 2014, 136, 12027-12034.
4 S. Cantekin, A. J. Markvoort, J. A. A. W. Elemans, A. E. Rowan and R. J. M. Nolte, J. Am. Chem. Soc., 2015, 137, 3915-3923.

5 C. J. Walter and J. K. M. Sanders, Angew. Chem., Int. Ed. Engl., 1995, 34, 217-219.

6 J. Kang and J. Rebek, Nature, 1997, 385, 50-52.

7 M. Yoshizawa, M. Tamura and M. Fujita, Science, 2006, 312, 251-254.

8 T. Bibby, J. Nield, F. Partensky and J. Barber, Nature, 2001, 413, 590.

9 Y. Umena, K. Kawakami, J.-R. Shen and N. Kamiya, Nature, 2011, 473, 55-60.

10 G. McDermott, S. Prince, A. Freer, A. HawthornthwaiteLawless, M. Papiz, R. Cogdell and N. Isaacs, Nature, 1995, 374, 517-521.

11 R. P. Bonar-Law, L. G. Mackay, C. J. Walter, V. Marvaud and J. K. Sanders, Pure Appl. Chem., 1994, 66, 803-810.

12 N. Aratani, D. Kim and A. Osuka, Acc. Chem. Res., 2009, 42, 1922-1934.

13 D. V. Kondratuk, L. M. A. Perdigao, M. C. O’Sullivan, S. Svatek, G. Smith, J. N. O'Shea, P. H. Beton and H. L. Anderson, Angew. Chem., Int. Ed. Engl., 2012, 51, 6696-6699.

14 F. Cacialli, J. Wilson, J. Michels, C. Daniel, C. Silva, R. Friend, N. Severin, P. Samori, J. Rabe, M. O'Connell, P. Taylor and H. Anderson, Nat. Mater., 2002, 1, 160-164.

15 T. Tanaka and A. Osuka, Chem. Soc. Rev., 2015, 44, 943-969.

16 A. Nowak-Krol, M. Grzybowski, J. Romiszewski, M. Drobizhev, G. Wicks, M. Chotkowski, A. Rebane, E. Gorecka and D. T. Gryko, Chem. Commun., 2013, 49, 8368-8370.

17 G. Sedghi, K. Sawada, L. J. Esdaile, M. Hoffmann, H. L. Anderson, D. Bethell, W. Haiss, S. J. Higgins and R. J. Nichols, J. Am. Chem. Soc., 2008, 130, 8582-8583.

18 M. J. Crossley and P. L. Burn, J. Chem. Soc., Chem. Commun., 1987, 39-40.

19 J. A. Shelnutt, X.-Z. Song, J.-G. Ma, S.-L. Jia, W. Jentzen, C. J. Medforth and C. J. Medforth, Chem. Soc. Rev., 1998, 27, 31-42.

20 M. Mazzanti, J.-C. Marchon, M. Shang, W. R. Scheidt, S. Jia and J. A. Shelnutt, J. Am. Chem. Soc., 1997, 119, 12400-12401.

21 C. M. Drain, S. Gentemann, J. A. Roberts, N. Y. Nelson, C. J. Medforth, S. Jia, M. C. Simpson, K. M. Smith, J. Fajer, J. A. Shelnutt and D. Holten, J. Am. Chem. Soc., 1998, 120, 3781-3791.

22 M. D. Liptak, X. Wen and K. L. Bren, J. Am. Chem. Soc., 2010, 132, 9753-9763.

23 N. Bampos, V. Marvaud and J. K. M. Sanders, Chem. - Eur. J., 1998, 4, 335-343.

24 A. Vidal-Ferran, N. Bampos and J. K. M. Sanders, Inorg. Chem., 1997, 36, 6117-6126.

25 S. S. Eaton and G. R. Eaton, J. Am. Chem. Soc., 1975, 97, 3660-3666.

26 P. Wacker, K. Dahms, M. O. Senge and E. Kleinpeter, J. Org. Chem., 2007, 72, 6224-6231.

27 Z. Zhou, X. Zhang, Q. Liu, Z. Yan, C. Lv and G. Long, Inorg. Chem., 2013, 52, 10258-10263.

28 C. J. Medforth, R. E. Haddad, C. M. Muzzi, N. R. Dooley, L. Jaquinod, D. C. Shyr, D. J. Nurco, M. M. Olmstead, 
K. M. Smith, J.-G. Ma and J. A. Shelnutt, Inorg. Chem., 2003, 42, 2227-2241.

29 A. Rosa, G. Ricciardi and E. J. Baerends, J. Phys. Chem. A, 2006, 110, 5180-5190.

30 S. J. Dammer, P. V. Solntsev, J. R. Sabin and V. N. Nemykin, Inorg. Chem., 2013, 52, 9496-9510.

31 Z. Li and H. A. Scheraga, THEOCHEM, 1988, 179, 333-352.

32 Z. Li and H. A. Scheraga, Proc. Natl. Acad. Sci. U. S. A., 1987, 84, 6611-6615.

33 D. J. Wales and J. P. K. Doye, J. Phys. Chem. A, 1997, 101, 5111-5116.

34 D. J. Wales, GMIN: A program for basin-hopping global optimisation, basin-sampling, and parallel tempering, http://wwwwales.ch.cam.ac.uk/software.html.

35 S. A. Trygubenko and D. J. Wales, J. Chem. Phys., 2004, 120, 2082-2094.

36 D. Sheppard, R. Terrell and G. Henkelman, J. Chem. Phys., 2008, 128, 134106.

37 G. Henkelman and H. Jónsson, J. Chem. Phys., 2000, 113, 9978-9985.

38 D. J. Wales, OPTIM: A Program for Optimising Geometries and Calculating Pathways, http://www-wales.ch.cam.ac.uk/OPTIM/.

39 L. J. Munro and D. J. Wales, Phys. Rev. B: Condens. Matter Mater. Phys., 1999, 59, 3969-3980.

40 Y. Kumeda, D. J. Wales and L. J. Munro, Chem. Phys. Lett., 2001, 341, 185-194.

41 D. Case, T. Darden, T. Cheatham III, C. Simmerling, J. Wang, R. Duke, R. Luo, K. Merz, D. Pearlman, M. Crowley, R. Walker, W. Zhang, B. Wang, S. Hayik, A. Roitberg, G. Seabra, K. Wong, F. Paesani, X. Wu, S. Brozell, V. Tsui, H. Gohlke, L. Yang, C. Tan, J. Mongan, V. Hornak, G. Cui, P. Beroza, D. Mathews, C. Schafmeister, W. Ross and P. A. Kollman, AMBER 9, University of California, 2006.

42 D. Pearlman, D. Case, J. Caldwell, W. Ross, T. Cheatham III, S. DeBolt, D. Ferguson, G. Seibel and P. Kollman, Comput. Phys. Commun., 1995, 91, 1-41.

43 D. Case, T. Cheatham, T. Darden, H. Gohlke, R. Luo, K. Merz Jr., A. Onufriev, C. Simmerling, B. Wang and R. Woods, J. Comput. Chem., 2005, 26, 1668-1688.

44 M. W. Schmidt, K. K. Baldridge, J. A. Boatz, S. T. Elbert, M. S. Gordon, J. H. Jensen, S. Koseki, N. Matsunaga, K. A. Nguyen, S. Su, T. L. Windus, M. Dupuis and J. A. Montgomery, J. Comput. Chem., 1993, 14, 1347-1363.

45 A. D. Becke, J. Chem. Phys., 1993, 98, 5648-5652.

46 C. Lee, W. Yang and R. G. Parr, Phys. Rev. B: Condens. Matter Mater. Phys., 1988, 37, 785-789.

47 S. H. Vosko, L. Wilk and M. Nusair, Can. J. Phys., 1980, 58, 1200-1211.

48 P. J. Stephens, F. J. Devlin, C. F. Chabalowski and M. J. Frisch, J. Phys. Chem., 1994, 98, 11623-11627.

49 C. I. Bayly, P. Cieplak, W. Cornell and P. A. Kollman, J. Phys. Chem., 1993, 97, 10269-10280.

50 J. Wang, R. M. Wolf, J. W. Caldwell, P. A. Kollman and D. A. Case, J. Comput. Chem., 2004, 25, 1157-1174.
51 R. Bryce, The School of Pharmacy \& Pharmaceutical Sciences, University of Manchester, Oxford Road, Manchester, M13 9PL, UK., 2014, http://pharmacy. man.ac.uk/amber/ (15 October 2007, date last accessed).

52 F. Lin and R. Wang, J. Chem. Theory Comput., 2010, 6, 1852-1870.

53 M. J. Frisch, G. W. Trucks, H. B. Schlegel, G. E. Scuseria, M. A. Robb, J. R. Cheeseman, J. A. Montgomery, Jr., T. Vreven, K. N. Kudin, J. C. Burant, J. M. Millam, S. S. Iyengar, J. Tomasi, V. Barone, B. Mennucci, M. Cossi, G. Scalmani, N. Rega, G. A. Petersson, H. Nakatsuji, M. Hada, M. Ehara, K. Toyota, R. Fukuda, J. Hasegawa, M. Ishida, T. Nakajima, Y. Honda, O. Kitao, H. Nakai, M. Klene, X. Li, J. E. Knox, H. P. Hratchian, J. B. Cross, V. Bakken, C. Adamo, J. Jaramillo, R. Gomperts, R. E. Stratmann, O. Yazyev, A. J. Austin, R. Cammi, C. Pomelli, J. W. Ochterski, P. Y. Ayala, K. Morokuma, G. A. Voth, P. Salvador, J. J. Dannenberg, V. G. Zakrzewski, S. Dapprich, A. D. Daniels, M. C. Strain, O. Farkas, D. K. Malick, A. D. Rabuck, K. Raghavachari, J. B. Foresman, J. V. Ortiz, Q. Cui, A. G. Baboul, S. Clifford, J. Cioslowski, B. B. Stefanov, G. Liu, A. Liashenko, P. Piskorz, I. Komaromi, R. L. Martin, D. J. Fox, T. Keith, M. A. Al-Laham, C. Y. Peng, A. Nanayakkara, M. Challacombe, P. M. W. Gill, B. Johnson, W. Chen, M. W. Wong, C. Gonzalez and J. A. Pople, Gaussian 03, Gaussian, Inc., Wallingford, CT, 2004.

54 B. Mennucci, Wiley Interdiscip. Rev.: Comput. Mol. Sci., 2012, 2, 386-404.

55 S. Miertus, E. Scrocco and J. Tomasi, Chem. Phys., 1981, 55, 117-129.

56 W. Jentzen, X.-Z. Song and J. A. Shelnutt, J. Phys. Chem. B, 1997, 101, 1684-1699.

57 G. Guilera, G. S. McGrady, J. W. Steed, R. P. L. Burchell, P. Sirsch and A. J. Deeming, New J. Chem., 2008, 32, 1573-1581.

58 M. J. Webb, S. Deroo, C. V. Robinson and N. Bampos, Chem. Commun., 2012, 48, 9358-9360.

59 S. Anderson, H. L. Anderson and J. K. M. Sanders, J. Chem. Soc., Perkin Trans. 1, 1995, 2247-2254.

60 M. Feigel, Angew. Chem., 1984, 96, 380.

61 H. L. Anderson, A. Bashall, K. Henrick, M. McPartlin and J. K. M. Sanders, Angew. Chem., Int. Ed. Engl., 1994, 33, 429-431.

62 S. Anderson, H. L. Anderson and J. K. M. Sanders, Acc. Chem. Res., 1993, 26, 469-475.

63 W.-J. van Zeist, R. Visser and F. Bickelhaupt, Chem. - Eur. J., 2009, 15, 6112-6115.

64 W.-J. van Zeist and F. M. Bickelhaupt, Org. Biomol. Chem., 2010, 8, 3118-3127.

65 A. N. Cammidge and O. Ozturk, Tetrahedron Lett., 2001, 42, 355-358.

66 G. R. Geier III, B. J. Littler and J. S. Lindsey, J. Chem. Soc., Perkin Trans. 2, 2001, 701-711.

67 B. J. Littler, Y. Ciringh and J. S. Lindsey, J. Org. Chem., 1999, 64, 2864-2872. 